Published in final edited form as:

Pediatr Cardiol. 2014 August ; 35(6): 934-942. doi:10.1007/s00246-014-0878-6.

\title{
Mixed Aortic Valve Disease in the Young: Initial Observations
}

\author{
Allison C. Hill, MDa, David W. Brown, MDa, Steven D. Colan, MDa, Kimberly Gauvreau, \\ ScD ${ }^{a}$, Pedro J. del Nido, MD ${ }^{b}$, James E. Lock, MDa, Rahul H. Rathod, MDa \\ aDepartment of Cardiology, Boston Children's Hospital; Department of Pediatrics, Harvard \\ Medical School, Boston MA \\ 'Department of Cardiac Surgery, Boston Children's Hospital; Department of Surgery, Harvard \\ Medical School, Boston MA
}

\section{Abstract}

Background-The short term surgical results for mixed aortic valve disease (MAVD) and long term effects on the left ventricle (LV) are unknown.

Methods-Retrospective review identified patients with at least both moderate aortic stenosis and aortic regurgitation prior to surgical intervention. A 1:1 comparison cohort of patients with MAVD, who were not sent for surgical intervention, was identified.

Results-Forty-five patients underwent surgical management for MAVD. A control group of 45 medically managed patients with MAVD was also identified. Both groups had elevated LV end diastolic volume (EDV), elevated LV mass, normal LV mass:volume ratio (MVR) and ejection fraction. Both groups had diastolic dysfunction by early diastolic pulsed-Doppler mitral inflow/ early diastolic tissue Doppler velocity $z$ score. LV end diastolic pressure (EDP) was correlated with age $(\mathrm{R}=0.4, p=0.05)$ and $\mathrm{LV}$ MVR $(\mathrm{R}=0.4, p=0.05)$, but not with aortic stenosis, aortic regurgitation, or a score combining gradient and LV size.

On 6-12 month postoperative echocardiograms, aortic valve gradients and aortic regurgitation significantly improved (gradient $65 \pm 17$ to $28 \pm 18 \mathrm{mmHg}, p=0.01$; median regurgitation grade moderate to mild, $p<0.01)$, LV EDV normalized, and LV mass significantly improved $(p<0.01)$. Diastolic dysfunction was unchanged. Symptoms did not correlate with any measured parameter; however preoperative symptoms resolved.

Conclusions-In conclusion, despite diastolic dysfunction, systolic function is invariably preserved and symptoms are not correlated with aortic valve function or LV EDP. Current surgical practice preserves LV mechanics and results in short term improvement in valve function and symptoms.

\section{Keywords}

CHD, valve; Aortic valve, repair; Ventricle, left; Pediatric

Address for correspondence and reprints: Rahul H. Rathod, MD, Boston Children's Hospital, Department of Cardiology, 300 Longwood Ave, Boston, MA 02115, Phone: (617) 355-4890; Fax: (617) 739-6282, rahul.rathod@ childrens.harvard.edu. 


\section{Introduction}

Mixed aortic valve disease (MAVD), comprised of both aortic stenosis (AS) and regurgitation (AR), is a rare primary disorder. Some patients develop MAVD as a long term consequence of the catheterization and surgical management of critical AS or surgery for AR.[1-9] Given these procedures began in the 1980s, there is a growing, yet significantly understudied, population of patients with MAVD. The effects of MAVD on the left ventricle (LV) differ from pure AS or AR. Left ventricular end-diastolic dimension in MAVD patients is smaller than in pure AR and larger than in pure AS.[7,9] LV shortening fraction is lower in MAVD patients compared to pure AS patients.[8]

Although Zilberszac et al. shed light on the natural history of MAVD in adults, current management and timing of surgical aortic valve repair in children are idiosyncratic due to the lack of understanding of the unnatural history and consequences of MAVD on LV mechanics.[10] This study characterizes the effects of surgery on valve performance and LV function.

\section{Methods}

We retrospectively reviewed all patients who had an echocardiogram with MAVD from 1/2003 to 9/2011 and who had surgery for MAVD. MAVD was defined as at least moderate AS (either apical maximal instantaneous gradient or suprasternal notch mean gradient $\geq 36$ $\mathrm{mm} \mathrm{Hg}$ depending on which had a better angle of interrogation and/or better Doppler envelope) and moderate AR (vena contracta $>3.1 \mathrm{~mm} /$ body surface area (BSA) ${ }^{0.5}$ or a descending aortic Doppler profile with holodiastolic flow reversal).[11] Exclusion criteria were other significant structural heart disease (residual mitral stenosis, residual coarctation, or complex congenital heart disease).

A control group of the 45 most recent medically managed patients with MAVD was identified. These patients may have had prior surgery for isolated AS or AR but were not referred for surgery for MAVD. Echocardiograms from the preoperative, inpatient postoperative, and 6-12 month postoperative periods were included as were the most recent echocardiograms for medical patients. The following variables were recorded from each echocardiogram: age, BSA, indexed LV end-diastolic volume (EDV)/BSA, LV EDV $z$ score, LV mass $z$ score, ejection fraction (EF), fractional shortening, $L V$ mass:volume ratio (MVR), LV MVR $z$ score, AS grade, aortic valve gradient, AR grade. The aortic valve gradient was defined as the higher number between the maximal instantaneous gradient across the aortic valve from the apical view or the mean gradient from the suprasternal notch view.[12] LV volumes were calculated using the 5/6-area-length method.[13]

Diastolic function was assessed using pulsed-Doppler of the mitral peak early (E) and peak late (A) inflow velocities and tissue Doppler imaging (TDI). Pulsed-wave TDI velocities (peak early diastolic velocity [E'], and peak late diastolic velocity [A']) were measured from the lateral mitral annulus and the interventricular septum from the apical 4-chamber view. Conventional indices of diastolic function were calculated including mitral valve peak $\mathrm{E}$ and A velocities, E:A ratio, E wave deceleration time, and E/E' ratio. Echocardiographic 
parameters were converted to $z$ scores as recommended by the American Society of Echocardiography[13] using normative data developed at Boston Children's Hospital. $[14,15]$

Primary disease process(es), intervention history, gender, New York Heart Association (NYHA) functional or modified Ross heart failure (for preverbal children) classification, and transplant/death were recorded. NYHA functional classification or modified Ross heart failure classification $\geq$ II was considered symptomatic. Preoperative LV end-diastolic pressure (EDP) was recorded when available. The study was approved by the Department of Cardiology Scientific Review Committee and Boston Children's Hospital Committee on Clinical Investigation.

\section{Statistical Analysis}

Sample size was estimated to detect changes in LV EF and LV mass $Z$ score from preoperative to 6-12 months postoperative echocardiograms. Calculations assumed paired, two-sided tests of means conducted at 0.05 significance level and $90 \%$ power. Assuming a standard deviation for change in LV EF of $12 \%,[16,17] 24$ patients would be required to detect an $8 \%$ difference. Assuming a standard deviation for change in LV mass $z$ score of 2.1,[9] 47 patients would be needed to detect a mean difference of 1.0.

Continuous variables were reported as mean \pm standard deviation for normally distributed variables and median (interquartile range) for not normally distributed data; categorical variables were reported as frequency (percent). Variables were compared with the paired $t$ test for the pre and postoperative echocardiograms and the unpaired $t$ test for the surgical vs medical patients. Baseline patient characteristics were compared for medical and preoperative surgical patients with Fisher's exact test or Wilcoxon rank sum test. Pearson correlation coefficients linked LV EDP, and echocardiographic data. Analyses were performed with SPSS 16.0 (SPSS, Inc., Chicago, Illinois) and STATA 11 (STATA Corporation, College Station, Texas).

\section{Results \\ Patient Characteristics}

From 1/2003 through 9/2011, 45 patients underwent surgery for at least moderate MAVD. Most (62\%) underwent surgical valvuloplasty/repair, whereas fewer underwent aortic valve replacement or Ross procedure (27\% and $11 \%$ respectively). Table 1 shows demographic and clinical data. Most patients in both groups had isolated aortic valve disease, had previous catheterization balloon dilations but had not had previous surgery. Eight surgical and 12 medical patients had no previous aortic valve interventions. Compared to medically managed patients, patients who went for surgery were younger $(p<0.01)$, had a history of more aortic valve surgeries $(p=0.04)$, and were more likely to be symptomatic with worsening NYHA functional or modified Ross heart failure classification $(p=0.02)$, as shown in Figure 1. 


\section{Echocardiographic Data}

Echocardiographic variables are shown in Tables 2 and 3. LV EDV $z$ scores were larger (3.5 \pm 2.5 vs. $2.5 \pm 1.6, p=0.05)$ and aortic valve gradients higher ( $65 \pm 17$ vs $55 \pm 17, p=0.01$ ) in surgical patients preoperatively than in medically managed patients. LV MVR $z$ score was preserved in both groups ( $z$ scores $1.8 \pm 4.6$ and $1.1 \pm 2.5$ respectively). For surgical patients, 6-12 month postoperative echocardiograms showed significant improvement in indexed LV EDV, LV EDV $z$ score, aortic valve gradients, and AR grade. The LV MVR $z$ score remained normal after surgery. Although the decrease in LV EF was significant (68 \pm 7 vs $62 \pm 5, p<0.01$ ), no patient had an LV EF $<55 \%$ on their 6-12 month postoperative echocardiogram.

\section{Diastolic Function}

Twenty-two (49\%) of the 45 surgical patients had preoperative catheterizations while 8 (18\%) of the medical patients had catheterizations. LV EDP was positively correlated with E/E' $z$ score $(\mathrm{R}=0.51, p=0.02)$, age $(\mathrm{R}=0.37, p=0.05)$, and LV MVR $z$ score $(\mathrm{R}=0.37$, $p=0.05$ ) (Figure 2). LV EDP tended to be normal before age 14 and abnormal after age 16 years. $\mathrm{LV}$ EDP was correlated with $\mathrm{E} / \mathrm{E}^{\prime} z$ score $(\mathrm{R}=0.51, p=0.02$, figure 2$)$ and mitral inflow E-wave deceleration time $z$ score $(\mathrm{R}=-0.43, p=0.04)$ on echocardiographic diastolic assessment. Diastolic function, measured by E/E' z score, did not change postoperatively.

\section{Symptoms}

Of the intervention group, fourteen patients (31\%) were symptomatic, with the majority of these patients classified as NYHA or modified Ross heart failure Class II. Only 3 patients (7\%) were Class III. The medical group had only six (13\%) symptomatic patients, all of whom were NYHA or modified Ross heart failure Class II. The age distribution of symptoms is shown in Figure 3. All symptomatic patients were over the age of eight years. Figure 4 depicts subanalyses of patients dichotomized by symptoms. Symptomatology did not correlate with LV EDP, E/E' $z$ score, aortic valve gradient, or AR. Despite the lack of hemodynamic correlation, symptomatic patients were more likely to undergo surgery than asymptomatic patients $(p=0.02)$.

\section{Discussion}

MAVD in the young is rare in the absence of prior procedures to palliate that valve. However, the increased use of catheterization or surgery to improve (as opposed to replace) markedly abnormal aortic valves is causing this patient population to expand rapidly.

$[1,2,7,18]$ Although we and others have recognized this trend, a comprehensive description of the clinical and physiologic characteristics of these patients remains, to our knowledge, unreported.

The primary findings of this study are: (1) symptoms have no correlation with severity of aortic valve dysfunction or LV EDP. (2) LV systolic function is preserved in all patients, both with and without surgical management. (3) Diastolic dysfunction is common, increases with patient age, but seems to be unrelated to the severity of valve dysfunction, although our 
measure of severity of valve dysfunction only captures one moment in time, as opposed to cumulative burden of disease. (4) Surgical management, generally valve repair, improves valve function, reduces LV volume and mass, and improves NYHA functional or modified Ross heart failure classification grade.

\section{Symptoms}

Adults with chronic AR tend to be asymptomatic for a long period of time.[19] Once symptoms begin, LV EF and survival decrease dramatically.[20,21] This has led to adult clinical practice guidelines including symptomatology as an indication for surgery.[22] Our data show that symptoms in children with MAVD tend to occur in later childhood and would be interesting to track with formal exercise testing. Our data indicated that symptoms do not correlate with severity of aortic valve dysfunction, systolic function, or diastolic dysfunction. Although this brings into question symptomatology as an indication for surgery in MAVD, symptoms resolve postoperatively and we lack longitudinal outcome data in patients who do not undergo surgery.

\section{Systolic function}

The adult experience with aortic valve replacement (AVR) has shed light on some predictors of LV systolic function recovery. Adults with chronic AR tend to have full recovery of systolic function by six months after AVR.[23] In those patients who do not have recovery by six months after AVR, the LV tends not to recover.[24] We also noted normalization of LV dilation and near normalization of LV mass by the 6-12 month follow-up time period. In adults, preoperative indexed LV size in systole and diastole were independent predictors of restored LV function.[23,25] Similarly, in adults with severe AS who have an AVR, a smaller preoperative LV EDV was a predictor of better postoperative LV functional recovery. $[17,26,27]$

In our surgical cohort, the preoperative LV EF was preserved and remained normal postoperatively in all of the patients. Although practitioners may have chosen surgical intervention prior to a significant decrease in $\mathrm{LV} \mathrm{EF}$, it is reasonable to assume that in the early stages of MAVD, LV EF is an insensitive marker of LV dilation, elevated filling pressures, or higher degree of valve dysfunction.

\section{Diastolic function}

Diastolic dysfunction as measured by E/E' $z$ score was present in most patients in our study and correlated with LV EDP. There was no significant change in E/E' $z$ score 6-12 months after surgery. We do not have invasive late postoperative assessments of LV EDP to correlate these findings. Other studies have shown that diastolic dysfunction is present in patients with congenital AS, and that it recovers after the outflow tract obstruction is relieved.[28-31] Some anecdotal data has also suggested that severe diastolic dysfunction is seen late after aortic valve balloon dilation in infancy.[32] Diastolic dysfunction is present in AS and MAVD patients more than pure AR patients and is associated with a higher LV mass zscore.[33] Our data suggest that in the MAVD population, diastolic dysfunction may take longer to recover than LV mass or volume as it persisted 6-12 months postoperatively. We 
also found that LV EDP is unrelated to valve function, but is related to age: before age 14, LV EDP is generally normal; after age 16 years, LV EDP tends to be increased.

\section{Surgical management}

Referral to surgery in this patient population was idiosyncratic and not based on any set criteria as there were few, if any, data that might inform indications for surgery in children. However, referral was not totally random: patients undergoing operation had higher aortic valve gradients, higher degrees of AR and an increased prevalence of symptomatology. Our current idiosyncratic strategy for surgical intervention, resulted in short term valve function improvement and recovery of LV size and LV mass.

Our findings of LV recovery after surgical intervention for MAVD are similar to data from other studies with different types of aortic valve disease. Bacha et al. described outcomes for patients with a history of congenital AS status post balloon dilation who subsequently developed predominant AR. In this population, LV dilation and amount of AR both decreased after surgical repair and remained reduced over time.[18] In our population of MAVD patients, we found a similar recovery in LV EDV after surgical intervention. In another population of patients with predominantly AR, freedom from aortic valve replacement at 5 and 7.5 years was $72 \%$ and $54 \%$ and was shorter in MAVD patients than pure AR.[9] On the other hand, in patients who have had a Ross procedure, those with MAVD had a 10-year freedom from reoperation that was similar to pure AS (97\% and 93\% respectively) and higher than pure AR (69\%).[34] The high freedom from reoperation rate is consistent with our finding of overall significant LV recovery after surgery for MAVD.

\section{Limitations}

Limitations of this study included its retrospective design, small number of patients and variability in patient characteristics. Not all patients had catheterizations. The lack of clinical guidelines for when to catheterize and refer for surgical intervention on the aortic valve made practice variation substantial between practitioners and over time. The contribution of placebo effect on improvement of symptoms postoperatively could not be assessed. Many patients were primarily followed at other institutions, thus the echocardiogram protocols differed and some data including duration of mixed aortic valve disease burden were unavailable. Longer term follow-up would clarify the course of diastolic dysfunction and patient outcomes, which then may shed light regarding the timing of surgical intervention for MAVD.

\section{Conclusion}

MAVD is surprisingly well tolerated at least for the first two decades of life. Postoperative recovery in terms of clinical status as well as LV volume, mass and valvar function is encouraging. Given current idiosyncratic management strategies, EF is preserved in MAVD patients and thus is not helpful in determining disease severity or optimal operative timing. Diastolic dysfunction progresses with age in MAVD patients, and does not recover in the immediate postoperative period. Further investigation of the outcomes in patients with diastolic dysfunction will aid in determining optimal surgical timing. Because MAVD is 
infrequent, a standardized and systematic approach to preoperative assessment and surgical management with targeted prospective data collection and frequent analyses may speed the generation of persuasive data.[35]

\section{Acknowledgments:}

Supported by a grant from the Argosy Foundation, Boston, MA, USA

\section{Abbreviations}

$\begin{array}{ll}\text { LV } & \text { Left ventricle } \\ \text { EDP } & \text { End diastolic pressure } \\ \text { EDV } & \text { End diastolic volume } \\ \text { MAVD } & \text { Mixed aortic valve disease } \\ \text { AS } & \text { Aortic stenosis } \\ \text { AR } & \text { Aortic regurgitation } \\ \text { MVR } & \text { Mass: volume ratio } \\ \text { BSA } & \text { Body surface area } \\ \text { NYHA } & \text { New York Heart Association } \\ \text { EF } & \text { Ejection fraction }\end{array}$

\section{References}

1. Alexiou C, Langley SM, Dalrymple-Hay MJ, Salmon AP, Keeton BR, Haw MP, Monro JL (2001) Open commissurotomy for critical isolated aortic stenosis in neonates. Ann Thorac Surg 71: 489493 [PubMed: 11235695]

2. Brown DW, Dipilato AE, Chong EC, Lock JE, McElhinney DB (2010) Aortic valve reinterventions after balloon aortic valvuloplasty for congenital aortic stenosis intermediate and late follow-up. J Am Coll Cardiol 56: 1740-1749 [PubMed: 21070926]

3. Davis CK, Cummings MW, Gurka MJ, Gutgesell HP (2008) Frequency and degree of change of peak transvalvular pressure gradient determined by two Doppler echocardiographic examinations in newborns and children with valvular congenital aortic stenosis. Am J Cardiol 101: 393-395 [PubMed: 18237607]

4. Hawkins JA, Minich LL, Tani LY, Day RW, Judd VE, Shaddy RE, McGough EC (1998) Late results and reintervention after aortic valvotomy for critical aortic stenosis in neonates and infants. Ann Thorac Surg 65: 1758-1762; discussion 1763 [PubMed: 9647096]

5. Justo RN, McCrindle BW, Benson LN, Williams WG, Freedom RM, Smallhorn JF (1996) Aortic valve regurgitation after surgical versus percutaneous balloon valvotomy for congenital aortic valve stenosis. Am J Cardiol 77: 1332-1338 [PubMed: 8677875]

6. McCrindle BW, Blackstone EH, Williams WG, Sittiwangkul R, Spray TL, Azakie A, Jonas RA (2001) Are outcomes of surgical versus transcatheter balloon valvotomy equivalent in neonatal critical aortic stenosis? Circulation 104: I152-158 [PubMed: 11568048]

7. McElhinney DB, Lock JE, Keane JF, Moran AM, Colan SD (2005) Left heart growth, function, and reintervention after balloon aortic valvuloplasty for neonatal aortic stenosis. Circulation 111: 451458 [PubMed: 15687133] 
8. Maskatia SA, Ing FF, Justino H, Crystal MA, Mullins CE, Mattamal RJ, O’Brian Smith E, Petit CJ (2011) Twenty-five year experience with balloon aortic valvuloplasty for congenital aortic stenosis. Am J Cardiol 108: 1024-1028 [PubMed: 21791328]

9. Bacha EA, McElhinney DB, Guleserian KJ, Colan SD, Jonas RA, del Nido PJ, Marx GR (2008) Surgical aortic valvuloplasty in children and adolescents with aortic regurgitation: acute and intermediate effects on aortic valve function and left ventricular dimensions. J Thorac Cardiovasc Surg 135: 552-559, 559 e551-553 [PubMed: 18329469]

10. Zilberszac R, Gabriel H, Schemper M, Zahler D, Czerny M, Maurer G, Rosenhek R (2013) Outcome of combined stenotic and regurgitant aortic valve disease. J Am Coll Cardiol 61: 14891495 [PubMed: 23500223]

11. Beroukhim RS, Graham DA, Margossian R, Brown DW, Geva T, Colan SD (2010) An echocardiographic model predicting severity of aortic regurgitation in congenital heart disease. Circ Cardiovasc Imaging 3: 542-549 [PubMed: 20581048]

12. Vlahos AP, Marx GR, McElhinney D, Oneill S, Goudevenos I, Colan SD (2008) Clinical utility of Doppler echocardiography in assessing aortic stenosis severity and predicting need for intervention in children. Pediatr Cardiol 29: 507-514 [PubMed: 18080153]

13. Lopez L, Colan SD, Frommelt PC, Ensing GJ, Kendall K, Younoszai AK, Lai WW, Geva T (2010) Recommendations for quantification methods during the performance of a pediatric echocardiogram: a report from the Pediatric Measurements Writing Group of the American Society of Echocardiography Pediatric and Congenital Heart Disease Council. J Am Soc Echocardiogr 23: 465-495; quiz 576-467 [PubMed: 20451803]

14. Sluysmans T, Colan SD (2009) Structural measurements and adjustment for growth In: Lai WW, Mertens LL, Cohen MS, Geva T (eds) Echocardiography in Pediatric and Congenital Heart Disease: From Fetus to Adult. Wiley-Blackwell, West Sussex, UK, pp 53-62

15. Foster BJ, Mackie AS, Mitsnefes M, Ali H, Mamber S, Colan SD (2008) A novel method of expressing left ventricular mass relative to body size in children. Circulation 117: 2769-2775 [PubMed: 18490525]

16. Connolly HM, Oh JK, Orszulak TA, Osborn SL, Roger VL, Hodge DO, Bailey KR, Seward JB, Tajik AJ (1997) Aortic valve replacement for aortic stenosis with severe left ventricular dysfunction. Prognostic indicators. Circulation 95: 2395-2400 [PubMed: 9170402]

17. Tarantini G (2003) Aortic valve replacement in severe aortic stenosis with left ventricular dysfunction: determinants of cardiac mortality and ventricular function recovery. Eur J Cardiothorac Surg 24: 879-885 [PubMed: 14643804]

18. Bacha EA, Satou GM, Moran AM, Zurakowski D, Marx GR, Keane JF, Jonas RA (2001) Valvesparing operation for balloon-induced aortic regurgitation in congenital aortic stenosis. $\mathrm{J}$ Thorac Cardiovasc Surg 122: 162-168 [PubMed: 11436050]

19. Ishii K, Hirota Y, Suwa M, Kita Y, Onaka H, Kawamura K (1996) Natural history and left ventricular response in chronic aortic regurgitation. Am J Cardiol 78: 357-361 [PubMed: 8759822]

20. Dujardin KS, Enriquez-Sarano M, Schaff HV, Bailey KR, Seward JB, Tajik AJ (1999) Mortality and morbidity of aortic regurgitation in clinical practice. A long-term follow-up study. Circulation 99: 1851-1857 [PubMed: 10199882]

21. Borer JS, Hochreiter C, Herrold EM, Supino P, Aschermann M, Wencker D, Devereux RB, Roman MJ, Szulc M, Kligfield P, Isom OW (1998) Prediction of indications for valve replacement among asymptomatic or minimally symptomatic patients with chronic aortic regurgitation and normal left ventricular performance. Circulation 97: 525-534 [PubMed: 9494022]

22. Goldbarg SH, Halperin JL (2008) Aortic regurgitation: disease progression and management. Nat Clin Pract Cardiovasc Med 5: 269-279 [PubMed: 18364707]

23. Cho S-H, Byun C-S, Kim K-W, Chang B-C, Yoo K-J, Lee S (2010) Preoperative indexed left ventricular dimensions to predict early recovery of left ventricular function after aortic valve replacement for chronic aortic regurgitation. Circulation 74: 2340-2345

24. Bonow RO, Dodd JT, Maron BJ, O'Gara PT, White GG, McIntosh CL, Clark RE, Epstein SE (1988) Long-term serial changes in left ventricular function and reversal of ventricular dilatation 
after valve replacement for chronic aortic regurgitation. Circulation 78: 1108-1120 [PubMed: 2972417]

25. Brown ML, Schaff HV, Suri RM, Li Z, Sundt TM, Dearani JA, Daly RC, Orszulak TA (2009) Indexed left ventricular dimensions best predict survival after aortic valve replacement in patients with aortic valve regurgitation. Ann Thorac Surg 87: 1170-1175; discussion 1175-1176 [PubMed: 19324145]

26. Ding WH, Lam YY, Kaya MG, Li W, Chung R, Pepper JR, Henein MY (2008) Echocardiographic predictors of left ventricular functional recovery following valve replacement surgery for severe aortic stenosis. Int J Cardiol 128: 178-184 [PubMed: 17706817]

27. Rothenburger M, Drebber K, Tjan TDT, Schmidt C, Schmid C, Wichter T, Scheld HH, Deiwick M (2003) Aortic valve replacement for aortic regurgitation and stenosis, in patients with severe left ventricular dysfunction. Eur J Cardiothorac Surg 23: 703-709 [PubMed: 12754021]

28. Friedman KG, Margossian R, Graham DA, Harrild DM, Emani SM, Wilkins-Haug LE, McElhinney DB, Tworetzky W (2011) Postnatal left ventricular diastolic function after fetal aortic valvuloplasty. Am J Cardiol 108: 556-560 [PubMed: 21624551]

29. Pacileo G, Calabro P, Limongelli G, Russo MG, Pisacane C, Sarubbi B, Calabro R (2003) Left ventricular remodeling, mechanics, and tissue characterization in congenital aortic stenosis. J Am Soc Echocardiogr 16: 214-220 [PubMed: 12618728]

30. de Kort E, Thijssen JM, Daniels O, de Korte CL, Kapusta L (2006) Improvement of heart function after balloon dilation of congenital valvar aortic stenosis: a pilot study with ultrasound tissue Doppler and strain rate imaging. Ultrasound Med Biol 32: 1123-1128 [PubMed: 16829326]

31. Friedman KG, McElhinney DB, Colan SD, Porras D, Powell AJ, Lock JE, Brown DW (2012) Left ventricular remodeling and improvement in diastolic function after balloon aortic valvuloplasty for congenital aortic stenosis. Circulation Cardiovascular interventions 5: 549-554 [PubMed: 22739787]

32. Robinson JD, Del Nido PJ, Geggel RL, Perez-Atayde AR, Lock JE, Powell AJ (2010) Left ventricular diastolic heart failure in teenagers who underwent balloon aortic valvuloplasty in early infancy. Am J Cardiol 106: 426-429 [PubMed: 20643258]

33. Friedman KG, McElhinney DB, Rhodes J, Powell AJ, Colan SD, Lock JE, Brown DW (2012) Left Ventricular Diastolic Function in Children and Young Adults With Congenital Aortic Valve Disease. Am J Cardiol:

34. Alsoufi B, Manlhiot C, Fadel B, Al-Ahmadi M, Tamim M, McCrindle BW, Canver CC, Al-Halees Z (2010) The Ross procedure in children: preoperative haemodynamic manifestation has significant effect on late autograft re-operation. Eur J Cardiothorac Surg 38: 547-555 [PubMed: 20409726]

35. Rathod RH, Farias M, Friedman KG, Graham D, Fulton DR, Newburger JW, Colan S, Jenkins K, Lock JE (2010) A novel approach to gathering and acting on relevant clinical information: SCAMPs. Congenital heart disease 5: 343-353 [PubMed: 20653701] 


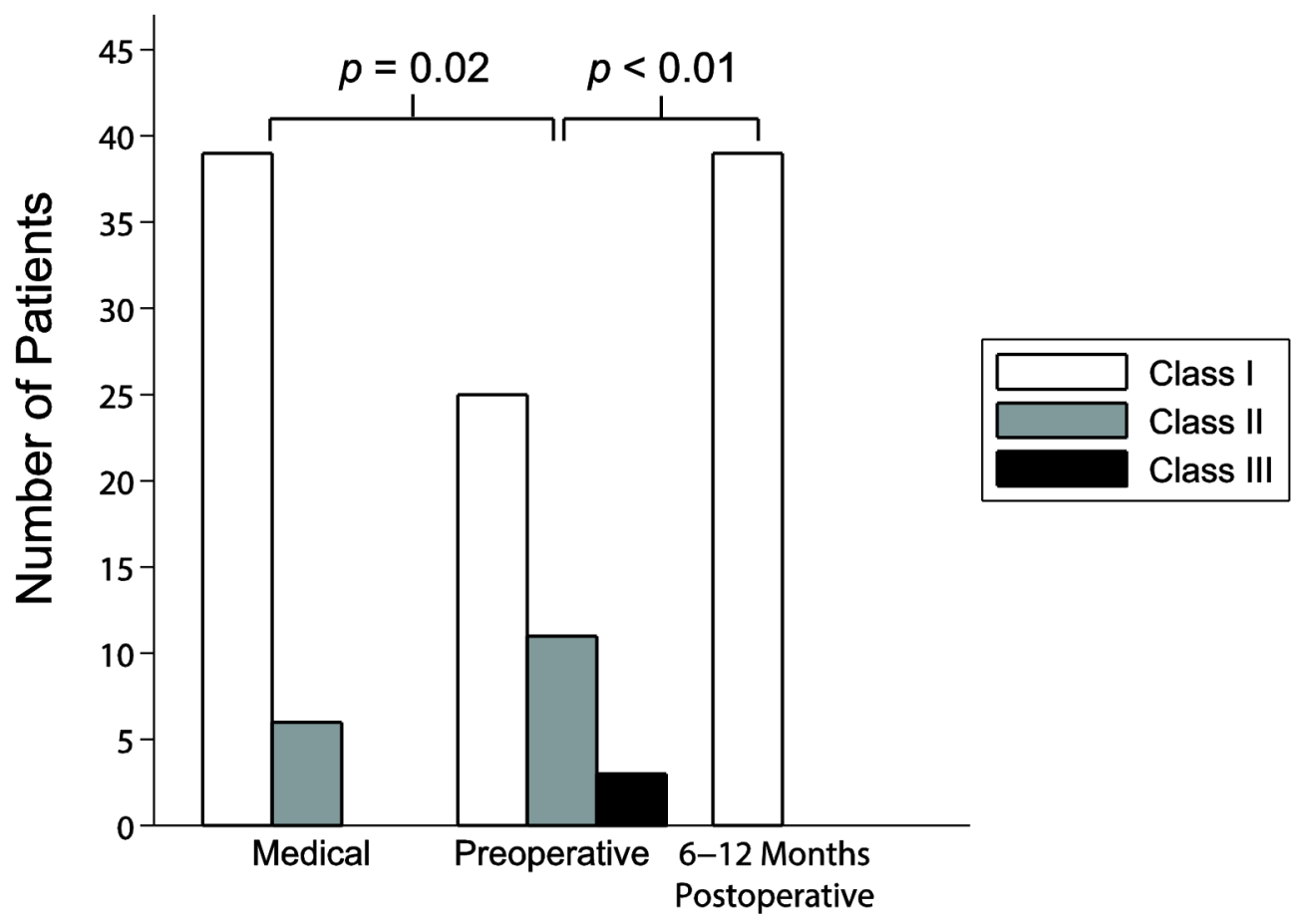

Figure 1: Symptomatic Classification

Bar graph comparing New York Heart Association (NYHA) or modified Ross heart failure functional classification for medical, preoperative, and 6-12 month postoperative surgical patients. $p=0.02$ comparing medical and preoperative classifications; $p<0.01$ comparing preoperative and 6-12 month postoperative classifications 
a)

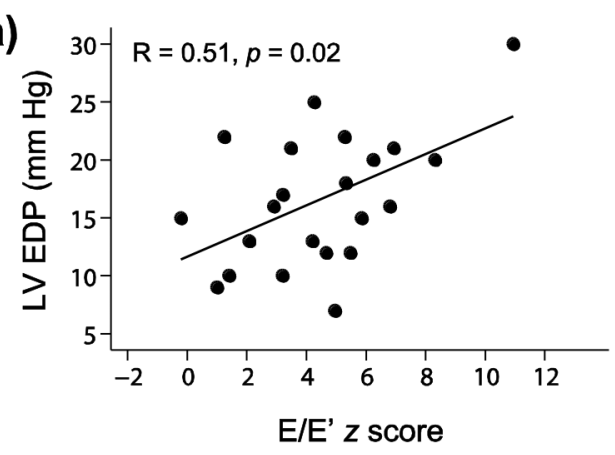

c)

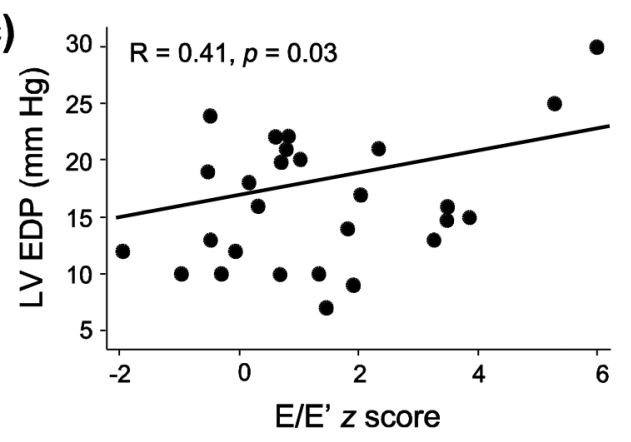

b)

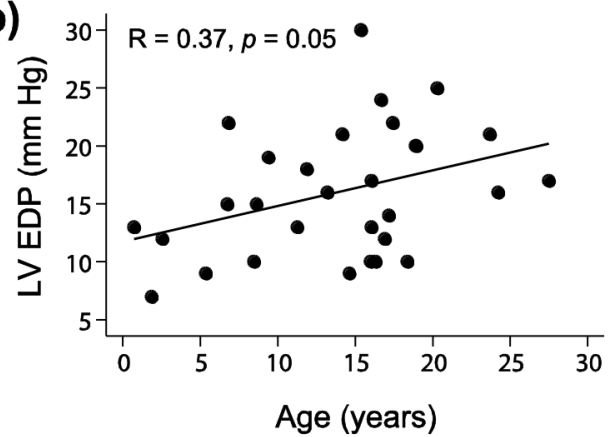

Figure 2: Left Ventricular End Diastolic Pressure Correlations

Scatter-plots showing correlations between a) left ventricular (LV) end diastolic pressure (EDP) vs early diastolic pulsed-Doppler mitral inflow (E)/early diastolic tissue Doppler velocity (E'); b) LV EDP vs age; c) LV EDP vs LV mass:volume (MVR) $z$ score. Solid line represents the least squares regression line. 


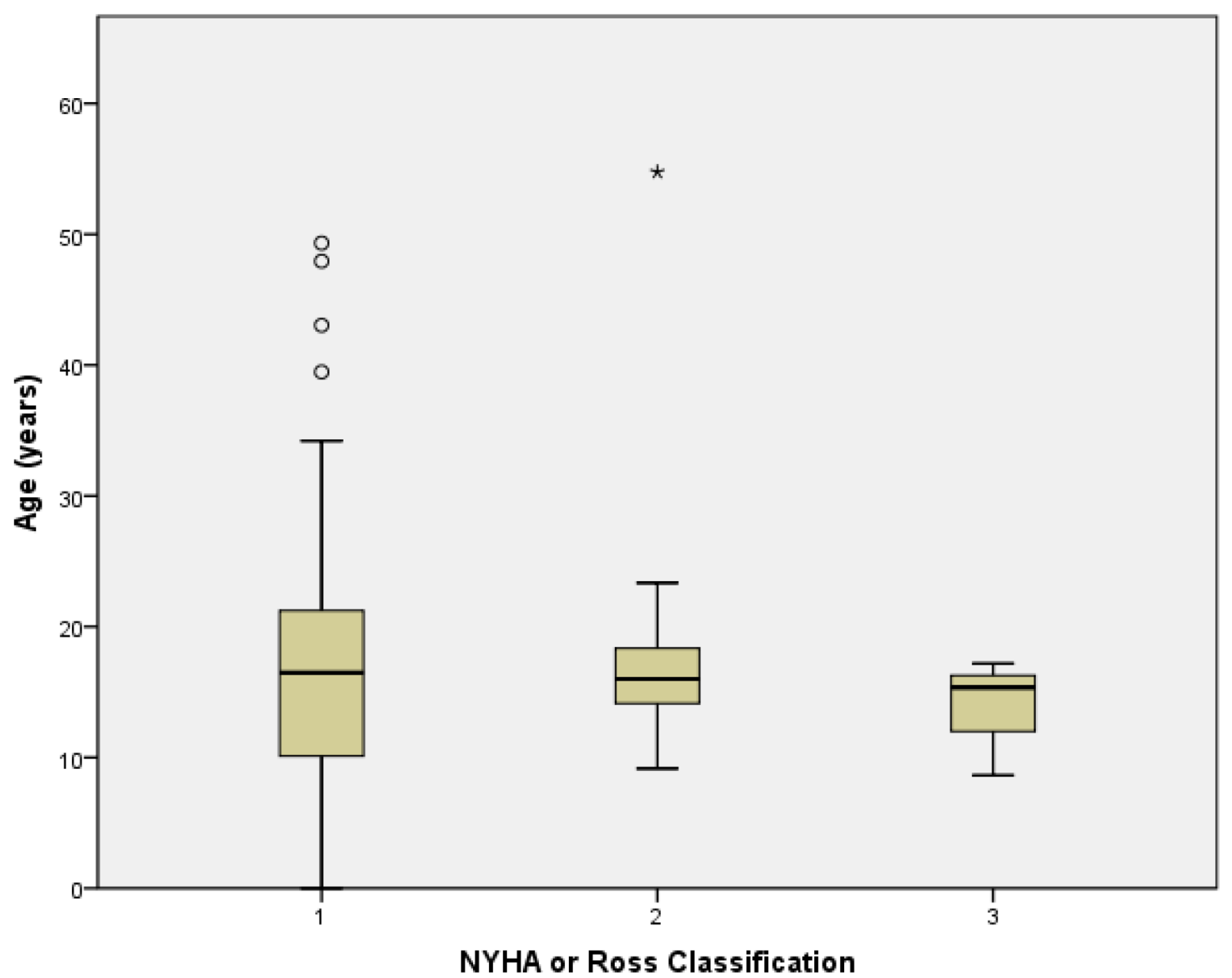

Figure 3: Age Distribution of Symptoms

Box plots showing patient age by NYHA or modified Ross heart failure classification. Boxes represent interquartile range, dark line represents median value, and whiskers represent range. 
a)

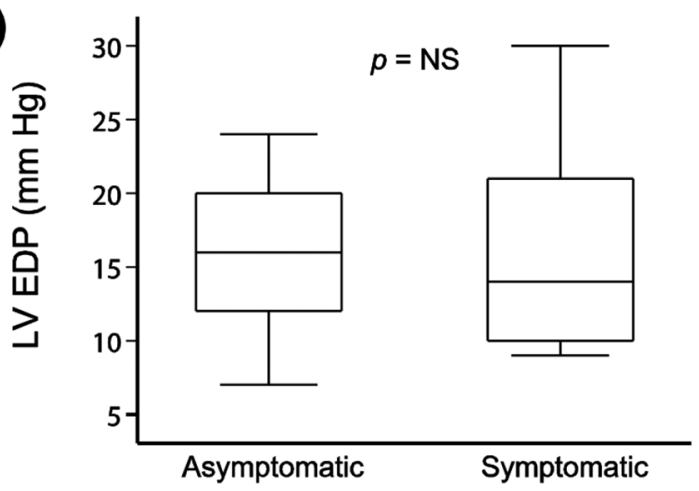

b)

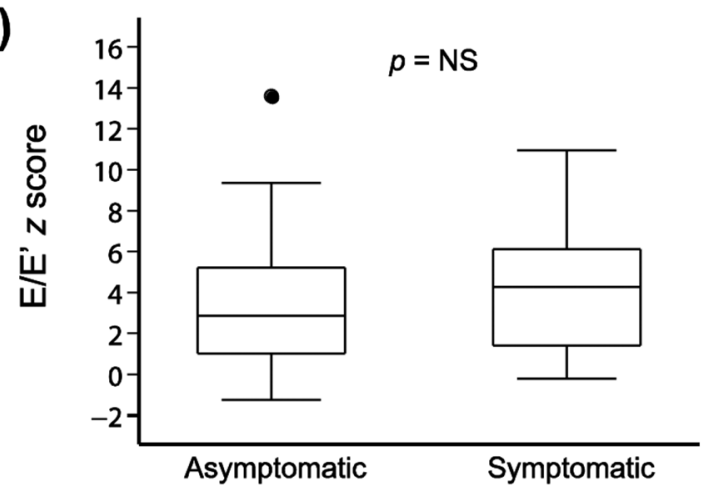

d)

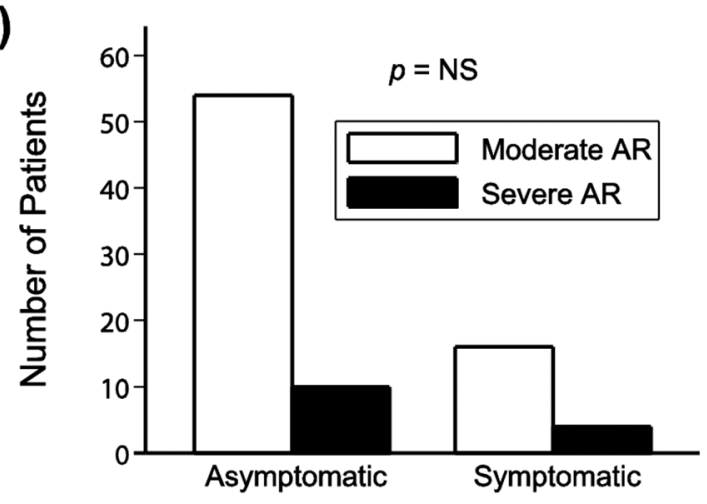

Figure 4: Comparisons of Asymptomatic vs Symptomatic Patients

Box plots showing a) left ventricular (LV) end diastolic pressure (EDP) vs symptoms; $b$ ) early diastolic pulsed-Doppler mitral inflow (E)/early diastolic tissue Doppler velocity (E') $Z$ score vs symptoms; and c) aortic valve gradient vs symptoms. Boxes represent interquartile range, dark line represents median value, and whiskers represent range. d) bar graph showing AR grade in asymptomatic and symptomatic patients. 
Table 1.

\section{Patient Characteristics}

\begin{tabular}{|c|c|c|c|}
\hline & $\begin{array}{l}\text { Surgical Patients } \\
\quad(n=45)\end{array}$ & $\begin{array}{l}\text { Medical Patients } \\
\qquad(\mathrm{n}=45)\end{array}$ & $p$ value \\
\hline Age (years) & $13.0(0.0-27.6)$ & $18.9(0.6-54.8)$ & $<0.01$ \\
\hline Males & $31(69 \%)$ & $38(84 \%)$ & 0.13 \\
\hline Associated congenital diagnoses & & & 0.28 \\
\hline Isolated aortic valve disease & $35(78 \%)$ & $40(90 \%)$ & \\
\hline Coarctation of the aorta & $2(4 \%)$ & $2(4 \%)$ & \\
\hline Ventricular septal defect & $1(2 \%)$ & $2(4 \%)$ & \\
\hline Mild mitral stenosis or regurgitation & $3(7 \%)$ & $0(0 \%)$ & \\
\hline Coronary anomalies & $3(7 \%)$ & $0(0 \%)$ & \\
\hline Patent ductus arteriosus & $1(2 \%)$ & $1(2 \%)$ & \\
\hline Native aortic valve morphology & & & 0.20 \\
\hline Unicuspid & $13(29 \%)$ & $21(47 \%)$ & \\
\hline Bicuspid (left-right fusion) & $16(35 \%)$ & $12(27 \%)$ & \\
\hline Bicuspid (right-non fusion) & $13(29 \%)$ & $10(22 \%)$ & \\
\hline Bicuspid (left-non fusion) & $0(0 \%)$ & $1(2 \%)$ & \\
\hline Tricuspid & $3(7 \%)$ & $1(2 \%)$ & \\
\hline \multicolumn{4}{|l|}{ Previous aortic valve interventions } \\
\hline Number of aortic valve surgeries & & & 0.04 \\
\hline 0 & $31(69 \%)$ & $39(87 \%)$ & \\
\hline 1 & $12(27 \%)$ & $5(11 \%)$ & \\
\hline 2 & $2(4 \%)$ & $1(2 \%)$ & \\
\hline Number of catheter balloon valvotomies & & & 0.42 \\
\hline 0 & $17(38 \%)$ & $15(33 \%)$ & \\
\hline 1 & $17(38 \%)$ & $22(49 \%)$ & \\
\hline$\geq 2$ & $11(24 \%)$ & $8(18 \%)$ & \\
\hline Age at first intervention (years) & 0.2 (prenatal-23.7) & $3.2(0.0-54.4)$ & 0.32 \\
\hline New York Heart Association or modified Ross heart failure classification & & & 0.02 \\
\hline Class I & $25(56 \%)$ & $39(87 \%)$ & \\
\hline Class II & $11(24 \%)$ & $6(13 \%)$ & \\
\hline Class III & $3(7 \%)$ & $0(0 \%)$ & \\
\hline Functional classification not available & $6(13 \%)$ & $0(0 \%)$ & \\
\hline
\end{tabular}

Values expressed as $\mathrm{n}(\%)$ or median (range). 
Table 2.

Echocardiographic Parameters of Medical and Surgical Patients

\begin{tabular}{|c|c|c|c|c|c|c|}
\hline & \multirow[b]{2}{*}{ Medical Patients } & \multicolumn{3}{|c|}{ Surgical Patients } & \multirow[b]{2}{*}{$p$ Value $^{\dagger}$} & \multirow[b]{2}{*}{$p$ Value } \\
\hline & & Pre-Operative & At Discharge & Post-Operative * & & \\
\hline Indexed LV EDV $\left(\mathrm{ml} / \mathrm{m}^{2}\right)$ & $107 \pm 26$ & $117 \pm 35$ & $84 \pm 31$ & $91 \pm 23$ & 0.14 & $<0.01$ \\
\hline LV EDV $z$ score & $2.5 \pm 1.6$ & $3.5 \pm 2.5$ & $1.0 \pm 2.2$ & $1.4 \pm 1.7$ & 0.05 & $<0.01$ \\
\hline LV mass $Z$ score & $3.4 \pm 1.9$ & $4.2 \pm 2.1$ & $4.1 \pm 2.0$ & $2.2 \pm 1.5$ & 0.07 & $<0.01$ \\
\hline LV mass:volume ratio & $1.0 \pm 0.2$ & $1.0 \pm 0.3$ & $1.4 \pm 0.4$ & $1.0 \pm 0.2$ & 0.78 & 0.57 \\
\hline LV mass:volume $z$ score & $1.8 \pm 4.6$ & $1.1 \pm 2.5$ & $4.1 \pm 3.2$ & $1.0 \pm 1.7$ & 0.40 & 0.69 \\
\hline LV ejection fraction $(\%)$ & $67 \pm 6$ & $68 \pm 7$ & $60 \pm 7$ & $62 \pm 6$ & 0.64 & $<0.01$ \\
\hline Aortic valve gradient $(\mathrm{mm} \mathrm{Hg})$ & $55 \pm 17$ & $65 \pm 17$ & $28 \pm 20$ & $28 \pm 18$ & 0.01 & $<0.01$ \\
\hline Aortic regurgitation grade ${ }^{\xi}$ & $2[2,3]$ & $2[2,3]$ & $1[0,2]$ & $1[0,2]$ & 1.00 & $<0.01$ \\
\hline
\end{tabular}

Values expressed as mean \pm standard deviation or median [interquartile range];

*

Echocardiographic evaluation 6-12 months after surgery;

${ }^{\dagger}$ Comparison between medical and surgical preoperative echocardiograms;

Comparison between surgical preoperative and 6-12 months postoperative echocardiograms;

$\xi_{\text {AR grading system: } 0=\text { none/trivial, } 1=\text { mild, } 2=\text { moderate, } 3=\text { severe. }}$

Abbreviations: $\mathrm{EDV}=$ end diastolic volume; $\mathrm{LV}=$ left ventricle; MAVD = mixed aortic valve disease 
Table 3.

Echocardiographic Diastolic Parameters of Medical and Surgical Parameters

\begin{tabular}{lccccc}
\hline & \multicolumn{2}{c}{ Surgical Patients } & & \\
& Medical Patients & Pre-Operative & Post-Operative $^{*}$ & $\boldsymbol{p}$ Value $^{\dagger}$ & $\boldsymbol{p}$ Value $^{*}$ \\
\hline Mitral inflow E:A ratio & $2.0 \pm 0.6$ & $2.1 \pm 0.7$ & $2.1 \pm 0.8$ & 0.55 & 0.73 \\
Mitral inflow E:A ratio $z$ score & $-0.5 \pm 1.1$ & $0.1 \pm 1.2$ & $-0.2 \pm 1.3$ & 0.05 & 0.35 \\
Mitral inflow E-wave decel time (msec) & $156 \pm 46$ & $145 \pm 62$ & $146 \pm 36$ & 0.46 & 0.54 \\
Mitral inflow E-wave decel time $z$ score & $-0.3 \pm 1.3$ & $-0.1 \pm 1.7$ & $-0.2 \pm 1.0$ & 0.62 & 0.91 \\
Mitral annular E' (cm/s) & $13.5 \pm 3.3$ & $12.9 \pm 3.1$ & $13.4 \pm 3.3$ & 0.46 & 0.65 \\
Mitral annular E' $z$ score & $-1.8 \pm 1.0$ & $-1.7 \pm 1.1$ & $-1.7 \pm 1.0$ & 0.82 & 0.89 \\
Septal E' (cm/s) & $9.8 \pm 2.4$ & $9.5 \pm 3.0$ & $9.0 \pm 2.0$ & 0.72 & 0.78 \\
Septal E' $z$ score & $-1.7 \pm 0.8$ & $-1.8 \pm 1.4$ & $-2.1 \pm 1.0$ & 0.82 & 0.68 \\
E/E' ratio & $11 \pm 4.5$ & $13.3 \pm 7.2$ & $12.3 \pm 4.7$ & 0.17 & 0.19 \\
E/E' ratio $z$ score & $3.5 \pm 4.2$ & $3.9 \pm 2.6$ & $3.4 \pm 1.6$ & 0.08 & 0.61 \\
\hline Values expressed as mean \pm standard deviation; & & & & \\
* & & & & & \\
Echocardiographic evaluation 6-12 months after surgery; & & & &
\end{tabular}

Abbreviations: A = pulsed Doppler mitral inflow peak A wave velocity; decel = deceleration; E = pulsed Doppler mitral inflow peak E wave velocity; E' = tissue Doppler mitral inflow peak E wave velocity. 